\title{
DESAIN MODEL SISTEM MARKETPLACE KERAJINAN TANGAN
}

\author{
Pandu Dwi Putra Nugroho ${ }^{1}$, Atik Ariesta ${ }^{2 *}$ \\ ${ }^{1}$ Fakultas Teknologi Informasi, Sistem Informasi, Universitas Budi Luhur, Jakarta, Indonesia \\ ${ }^{2}$ Fakultas Teknologi Informasi, Manajemen Informatika, Universitas Budi Luhur, Jakarta, Indonesia \\ Email: ${ }^{1}$ pandudpn@ @andudpn.com, ${ }^{2 *}$ atik.ariesta@budiluhur.ac.id

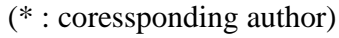

\begin{abstract}
Abstrak-Teknologi yang berkembang saat ini mengakibatkan transaksi jual beli mejadi lebih mudah dan lebih aman. Marketplace merupakan media tempat transaksi antara penjual dan pembeli berbasis internet. Produk yang ditawarkan sangat banyak seperti makanan, pakaian, sepatu, hingga peralatan rumah tangga. Dari sekian banyaknya produk yang dijual pada marketplace, produk lokal seperti kerajinan tangan masih kalah saing dari produk-produk lainnya. Kurang minatnya pada produk-produk lokal menjadi salah satu kalahnya kerajinan tangan dengan produk-produk yang ada pada marketplace. Business Model Canvas (BMC) digunakan untuk menggambarkan model bisnis yang akan dikembangkan pada marketplace, kemudian Unified Modeling Language (UML) digunakan untuk menggambarkan sistem informasi marketplace yang akan dibangun. Marketplace yang dibuat khusus untuk kerajinan tangan dapat meningkatkan daya saing dengan produk-produk yang ada pada marketplace lainnya. Selain itu juga dapat memperkenalkan hasil-hasil kerajinan tangan Indonesia
\end{abstract}

Kata Kunci: marketplace, kerajinan tangan, BMC, UML

\begin{abstract}
The technology that is currently developing makes buying and selling transactions easier and safer. Marketplace is a medium for internet-based transactions between sellers and buyers. The products offered are numerous, such as food, clothing, shoes, to household appliances. Of the many products sold on the marketplace, local products such as handicrafts are still less competitive than other products. This lack of interest in local products is one of the disadvantages of handicrafts products in the marketplace. The Business Model Canvas (BMC) is used to describe the business model that will be developed in the marketplace, then the Unified Modeling Language (UML) is used to describe the marketplace information system that will be built. Marketplaces made specifically for handicrafts can increase competitiveness with products in other marketplaces. Besides that, it can also introduce Indonesian handicrafts.
\end{abstract}

Keywords: marketplace, handicraft, BMC, $U M L$

\section{PENDAHULUAN}

Kerajinan tangan adalah hal yang berkaitan dengan buatan tangan atau kegiatan yang berkaitan dengan barang yang dihasilkan melalui keterampilan tangan. Kerajinan yang dibuat biasanya terbuat dari berbagai bahan. Dari kerajinan ini dapat menghasilkan hiasan atau benda seni maupun barang pakai. Kerajinan tangan bisa terbuat dari barang-barang bekas seperti botol bekas, kardus, dan plastik makanan.

Kegiatan jual beli merupakan suatu kegiatan rutin yang terjadi pada setiap harinya. Kegiatan jual beli akan terlaksana apabila terjadi kesepakatan antara kedua belah pihak untuk melakukan pertukaran barang atau jasa dengan uang.

Seiring dengan berkembangnya teknologi yang ada, sarana yang dapat digunakan untuk melakukan kegiatan jual beli pun berkembang menjadi lebih modern. Kegiatan jual beli tidak mengharuskan penjual dan pembeli bertemu secara langsung untuk melakukan transaksi. Berkat bantuan dari teknologi internet kegiatan jual beli dapat dilakukan secara online sehingga pembeli tidak perlu repot-repot untuk mendatangi suatu toko atau tempat berjualan.

Marketplace sebagai media tempat transaksi antara penjual dan pembeli berbasis internet. Produk yang ditawari oleh penjual mulai dari barang kebutuhan pokok seperti makanan atau kebutuhan rumah tangga hingga barang sekunder seperti alat penunjang hobi atau hiasan furniture yang dijual dalam suatu situs dimana situs tersebut merpukan konektor antara penjual dan calon pembeli.

Pada penelitian mengenai analisis sistem informasi e-marketplace pada Usaha Kecil Menengah (UMK) kerajinan tangan pada tahap perancangannya menggunakan Unified Modeling Language (UML) seperti Use Case Diagram, Activity Diagram, dan Class Diagram. E-Marketplace yang dibuat dibangun dengan menggunakan Bahasa Pemrograman PHP dan MySQL sebagai databasenya. [1]

Penelitian lain juga membahas tentang rancang bangun aplikasi marketplace penyedia jasa les private di kota pontianak. Marketplace dibangun dengan menggunakan Bahasa Pemrograman PHP, Framework Laravel dan database MySQL. Pengujian aplikasi yang dirancang menggunakan Robustness Testing untuk memastikan tidak ada kesalahan pada proses input. [2]

Qlapa adalah salah satu marketplace kerajinan tangan yang ada di Indonesia. Alasan Qlapa didirikan karena dua hal, yaitu untuk meningkatkan kepedulian terhadap pengerajin lokal dan memanfaatkan marketplace sebagai 
tempat yang tepat untuk melakukan transaksi jual beli antara para perajin atau penjual kerajinan tangan dengan calon pembeli. Tapi saat ini Qlapa sudah mengalami kebangkrutan dikarenakan berbagai macam factor diantaranya managemen internal yang masih belum efektif dan efisien. [3]

Masalah-masalah yang ada pada saat ini seperti belum adanya marketplace khusus untuk pengerajin lokal memasarkan hasil karyanya, sehingga kerajinan tangan ini masih kalah saing dengan penjualan barang lain, dan tidak adanya informasi yang dibutuhkan untuk mengambil keputusan sehingga keputusan yang dibuat oleh perusahaan mengakibatkan pailit, seperti berapa banyak jumlah pengrajin yang masih aktif atau jumlah penjual produk kerajinan tangan. Seberapa banyak yang tertarik pada produk-produk kerajinan tangan. Berapa banyak jumlah biaya pengiriman dari masing-masing jasa pengiriman. Berapa banyak jumlah transaksi berhasil atau gagal perhari, perbulan dan pertahun. Berapa banyak jumlah biaya pengeluaran dan pemasukan perhari, perbulan dan pertahun.

Adapun tujuan dalam penelitian adalah membuat sebuah marketplace yang hanya diperuntukan hasil-hasil kerajinan tangan dan menjadi jembatan antara penjual dan pembeli. Selain itu juga membuat sebuah sistem untuk meghindari kesalahan dalam mengambil keputusan yang berakibat pailit.

\section{METODE PENELITIAN}

Metode penelitian yang dilakukan dengan melakukan pendekatan pada studi kasus. Dimulai dengan mendefinisikan masalah yang terjadi pada obyek penelitian, kemudian dari masalah tersebut diberikan sebuah solusi dengan membuat model yang sesuai dengan kebutuhan obyek. Penelitian akan dibagi menjadi tiga tahap yaitu Pengumpulan Data, Analisis dan Perancangan Sistem, terakhir adalah Evaluasi Prototype.

\subsection{Pengumpulan Data}

Pada tahap pengumpulan data kegiatan yang dilakukan adalah mencari kajian pustaka yang berhubungan dengan marketplace sejenis, kemudian melakukan observasi pada marketplace yang sudah berjalan dengan cara melakukan transaksi secara langsung. Obyek penelitian yang dipilih adalah marketplace kerajinan tangan.

\subsection{Analisis dan Perancangan Sistem}

Pada tahap ini menggunakan Business Model Canvas (BMC) untuk mendapatkan model bisnis yang akan digunakan pada marketplace dengan menggunakan 9 elemen pada BMC yaitu: Value Proposition, Customer Segment, Customer Relationship, Channels, Key Activities, Key Resource, Key Partnership, Cost Structure, dan Revenue Stream. [4] Penggunaan Business Model Canvas dapat memberikan gambaran mengenai model bisnis perusahaan dan hubungan yang terjadi antar-blok dengan cara yang lebih atraktif. [5]

Setelah mengetahui model bisnis yang dikehendaki maka dilanjutkan dengan menganlisa dan merancang marketplace menggunakan diagram-diagram Unified Modeling Language (UML) seperti Use Case Diagram yang digunakan untuk menggabarkan sistem marketplace yang akan dibangun, Class Diagram digunakan untuk menggambarkan obyek yang terlibat pada marketplace, dan Sequence Diagram digunakan untuk menggambarkan rancangan program.

UML adalah sebuah bahasa standard untuk pengembangan sebuah software yang dapat menyampaikan bagaimana membuat dan membentuk model-model, tetapi tidak menyampaikan apa dan kapan model yang seharusnya dibuat yang merupakan salah satu proses implementasi pengembangan software. [6]

Bagian terakhir pada tahap ini adalah merancang prototype marketplace berdasarkan model bisnis, analisa, dan rancangan yang dilakukan. Pembuatan prototype marketplace menggunakan bahasa pemrograman PHP dan database MySQL.

\subsection{Evaluasi Prototype}

Evaluasi Prototype menggunakan pengujian black box. Pengujian black box yang dilakukan adalah menginput data yang digunakan pada marketplace ke prototype yang sudah dibuat sehingga berdasarkan data yang diinput bisa mendapatkan informasi yang sesuai. Sistem dengan model prototype memperbolehkan pengguna untuk mengetahui bagaimana sistem berjalan dengan baik. [7] 


\section{HASIL DAN PEMBAHASAN}

\subsection{Business Model Canvas (BMC)}

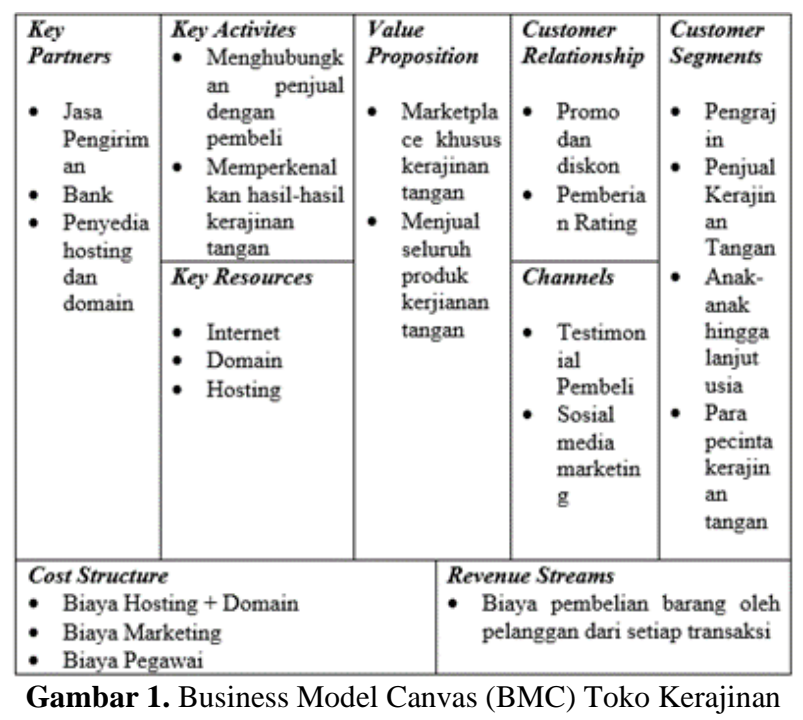

Pada Gambar 1 yaitu gambar Business Model Canvas (BMC) sebagai model bisnis yang dibuat untuk marketplace karajinan tangan, terdapat 9 elemen yaitu Value Proposition, Customer Segment, Customer Relationship, Channels, Key Activities, Key Partners, Key Resources, Cost Structures, dan Revenue Streams.[4]

Berikut penjelasan dari masing-masing elemen pada model bisnis marketplace kerajinan tangan:

a. Value Proposition

Elemen value proposition digunakan untuk menggabungkan atnara produk dan layanan yang menciptakan nilai untuk segmen pelanggan. Pada marketplace kerajinan tangan, value porpositionnya yaitu menjual khusus kerajinan tangan, menjual seluruh produk kerajinan tangan.

b. Customer Segment

Elemen Customer Segment digunakan untuk menentukan sekelompok orang atau organisasi berbeda yang ingin dijangkau atua dilayani oleh perusahaan. Pada marketplace kerajinan tangan akan menjangkau pengrajin, penjual kerajinan tangan, anak-anak hingga lanjut usia, pecinta kerajinan tangan.

\section{c. Customer Relationship}

Pada elemen ini digunakan untuk menentukan jenis hubungan yang dibagun perusahaan dengan pelanggan. Marketplace kerajinan tangan menggunakan promo, diskon, dan pemberian rating untuk berhubungan dengan pelanggan.

\section{d. Channels}

Channels digunakan untuk menentukan cara bagaimana perusahaan berkomunikasi dengan segemen pelanggan sehingga dapat menjangkau dan memberikan value. Pada Marketplace untuk menjangkau pelanggan dan juga berkomunikasi menggunakan website marketplace yang dibuat, dimana pada website tersebut disediakan tempat untuk memberikan testimonial pada produk. Selain itu digunakan juga Social Media untuk berkomunikasi.

\section{e. Key Activities}

Pada elemen key activities digunakan untuk menentukan hal-hal terpenting yang harus dilakukan oleh perusahaan agar model bisnisnya dapat bekerja sesuai dengan tujuan perusahaan. Marketplace kerajinan tangan menentukn hal-hal terpenting agar model bisnis dapat berjalan yaitu dapat menghubungkan antara penjual dengan pembeli, kemudian memperkenalkan hasil-hasil kerajinan tangan.

f. Key Partners

Key Partners digunakan untuk menentukan jaringan pemasok dan mitra yang membuat model bisnis suatu perusahaan dapat bekerja. Pada marketplace kerajinan tangan key partners yang diperlukan adalah jasa pengiriman agar aktifitas penjualan dan pemelian kerajinan tangan dapat terjadi, bank digunakan untuk pembayaran, dan penyedia hosting dan domain sehingga dapat memperkenalkan hasil-hasil kerajinan tangan. 


\section{g. $\quad$ Key Resources}

Elemen key resource menggambarkan sumber daya yang diperlukan agar model bisnis dapat berfungsi. Pada marketplace kerajinan tangan key resource yang diperlukan adalah internet, domain dan hosting.

h. Cost Structure

Cost Structure digunakan untuk menentukan semua biaya yang dikeluarkan oleh perusahaan untuk mengoperasikan model binsi. Pada marketplace kerajinan tangan biaya yang dikeluarkan yaitu biaya hosting dan domain, biaya marketing, dan biaya pegawai.

i. Revenue Streams

Revenue Stream merupakan elemen yang digunakan untuk menentukan sumber pendapatan yang dihasilkan dari masing-masing segment pelanggan. Marketplace kerajinan tangan sumber pendapatannya adalah melalui pembelian barang pada marketplace oleh pelanggan.

\subsection{Use Case Diagram}

Salah satu diagram penting yang digunakan untuk mengilustrasikan kebutuhan (requirements) dari sistem adalah use case (UC) diagram, yang menjelaskan secara visual konteks dari interaksi antara aktor dengan sistem. [8] Rancangan kebutuhan untuk marketplace dibagi menjadi 3 (tiga) use case diagram berasarkan kebutuhan dari user pengguna marketplace yaitu penjual (Gambar 2), pembeli (Gambar 3) dan admin Gambar 4).

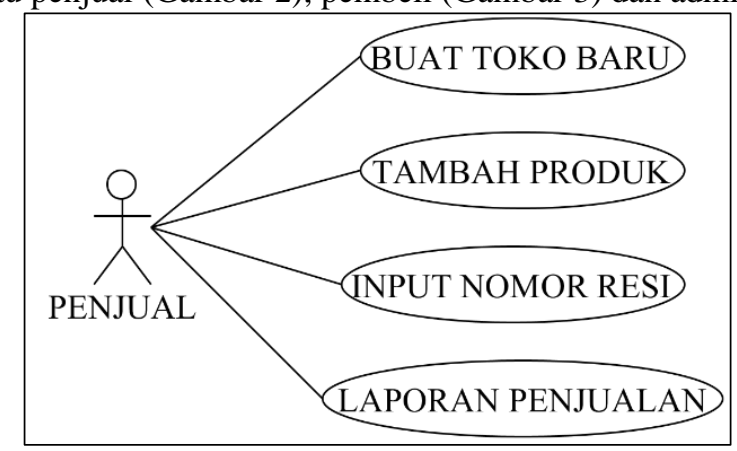

Gambar 2. Use Case Diagram User Penjual

Pada Gambar 2 merupakan Use Case Diagram User Penjual menggambarkan kebutuhan sistem yang dilihat dari user penjual. Kebutuhan dari user penjual adalah Buat Toko Baru untuk mendaftarkan toko pada marketplace, tambah Produk untuk menambah produk pada toko, Input Nomor Resi untuk memasukan nomor resi pengiriman produk dari toko ke pembeli, dan terakhir adalah Laporan Penjualan untuk melihat laporan penjualan sesuai dengan periodenya.

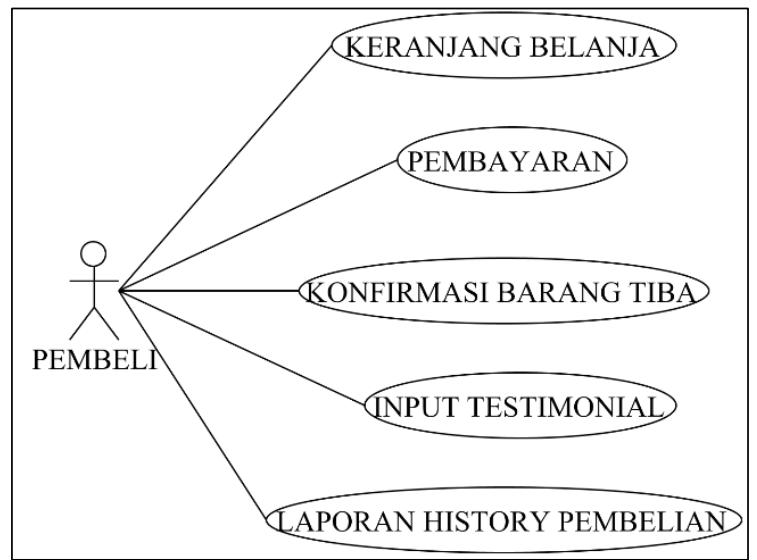

Gambar 3. Use Case Diagram User Pembeli

Pada Gambar 3 adalah Use Case Diagram User Pembeli yang digunakan untuk menggambarkan kebutuhan marketplace berdasarkan pembeli. Keranjang Belanja digunakan pembeli untuk memasukan produk yang dibeli sementara kedalam keranjang belana. Pembayaran digunakan pembeli untuk melakukan konfirmasi pembayaran. 
Konfirmasi Barang Tiba digunakan untuk pembeli melakukan konfirmasi bahwa barang yang dikirim oleh penjual sudah diterima oleh pembeli. Input Testimonial digunakan pembeli untuk memberikan testimonial dari produk yang dibeli, testimonial dapat dilakukan ketika barang sudah diterima oleh pembeli. Terakhir adalah Laporan History Pembelian yang dapat digunakan oleh pembeli untuk melihat data pembelian yang pernah dilakukan.

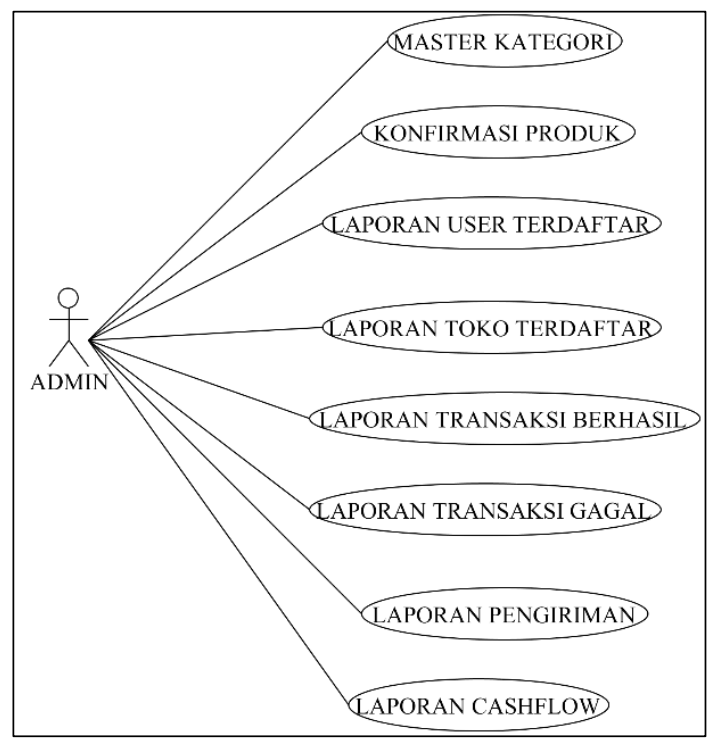

Gambar 4. Use Case Diagram User Admin

Pada Gambar 4 adalah Use Case Diagram User Admin merupakan kebutuhan yang diperlukan oleh marketplace berdasarkan user admin. Master kategori digunakan oleh admin untuk menambahkan kategori sehingga dapat digunakan oleh penjual ketika melakukan Tambah Produk. Konfirmasi Produk digunakan untuk admin melakukan konfirmasi produk yang dijual oleh penjual. Laporan User Terdaftar untuk melihat data user terdaftar pada marketplace. Laporan Toko Terdaftar digunakan untuk melihat toko yang sudah terdaftar pada marketplace. Laporan Transaksi Berhasil digunakan untuk melihat data transaksi dengan status berhasil yang dilakukan oleh pembeli. Laporan Transaksi Gagal digunakan untuk melihat data transaksi dengan status gagal yang dilakukan oleh pembeli. Laporan Pengiriman digunakan untuk melihat data pengiriman yang dilakukan oleh penjual. Terakhir Laporan Cashflow digunakan untuk melihat aliran uang pada marketplace.

\subsection{Class Diagram}

Class Diagram merupakan hubungan antar kelas dan penjelasan detail tiap-tiap kelas didalam model desain dari suatu sistem, juga memperlihatkan aturan-aturan dan tanggung jawab entitas yang menentukan perilaku sistem.[9]

Pada Gambar 5 adalah Class Diagram marketplace yang memperlihatkan detail dari tiap-tiap kelas dari model desain website marketplace. Terdapat class toko yang digunakan untuk menggambarkan entitas toko, class user yang menggambarkan entitas user pengguna website, class produk yang menggambarkan entitas produk yang tersedia pada website, class pesanan yang menggambarkan entitas pesanan yang dilakukan oleh pembeli, class detail pesanan yang menggambarkan entitas detail pesanan produk yang dilakukan oleh pembeli, class pembayara untuk menggambarkan entitas pembayaran yang dilakukan oleh pembeli, class komentar yang menggambarkan entitas komentar yang diberikan oleh pembeli pada setiap produk yang dipesannya, class kategori untuk menggambarkan entitas kategori sebagai pengelompokan produk yang ada pada website, terakhir class attachment untuk menggambarkan entitas gambar yang akan disertakan pada produk.

\subsection{Sequence Diagram}

Sequence Diagram digunakan untuk menggambarkan interaksi antara aktor dan sistem di dalam dan di sekitar aplikasi yang berupa message yang digambarkan terhadap waktu. Sequence Diagram terdiri antara dimensi vertikal (waktu) dan dimensi horizontal (objek-objek yang terkait). Message adalah tindakan yang dipanggil pada objek tujuan, seperti sebuah perintah.[10]

Sesuai dengan Use Case Diagram Penjual (Gambar 2) digambarkan kebutuhan tambah produk maka dibuatkan interface atau rancangan layar yang digunakan untuk tambah produk. Pada Rancangan Layar Tambah 
INDONESIA JOURNAL INFORMATION SYSTEM (IDEALIS)

Volume 4, Nomor 4, Juli 2021

ISSN 2684-7280 (online)

Halaman 157- 166

available online at http://jom.fti.budiluhur.ac.id/index.php/IDEALIS/index

Produk (Gambar 6) merupakan sebuah formulir yang dapat digunakan untuk melakukan input Nama Produk, Kategori, Harga, Stok, Berat, Deskripsi Produk, dan Foto dari produk yang akan ditambahkan. Terdapat juga tombol simpan yang digunakan untuk menyimpan data yang telah diinput.

Interaksi antara user penjual dengan website pada saat melakukan tambah produk dapat dilihat pada Sequence Diagram Tambah Produk (Gambar 7).

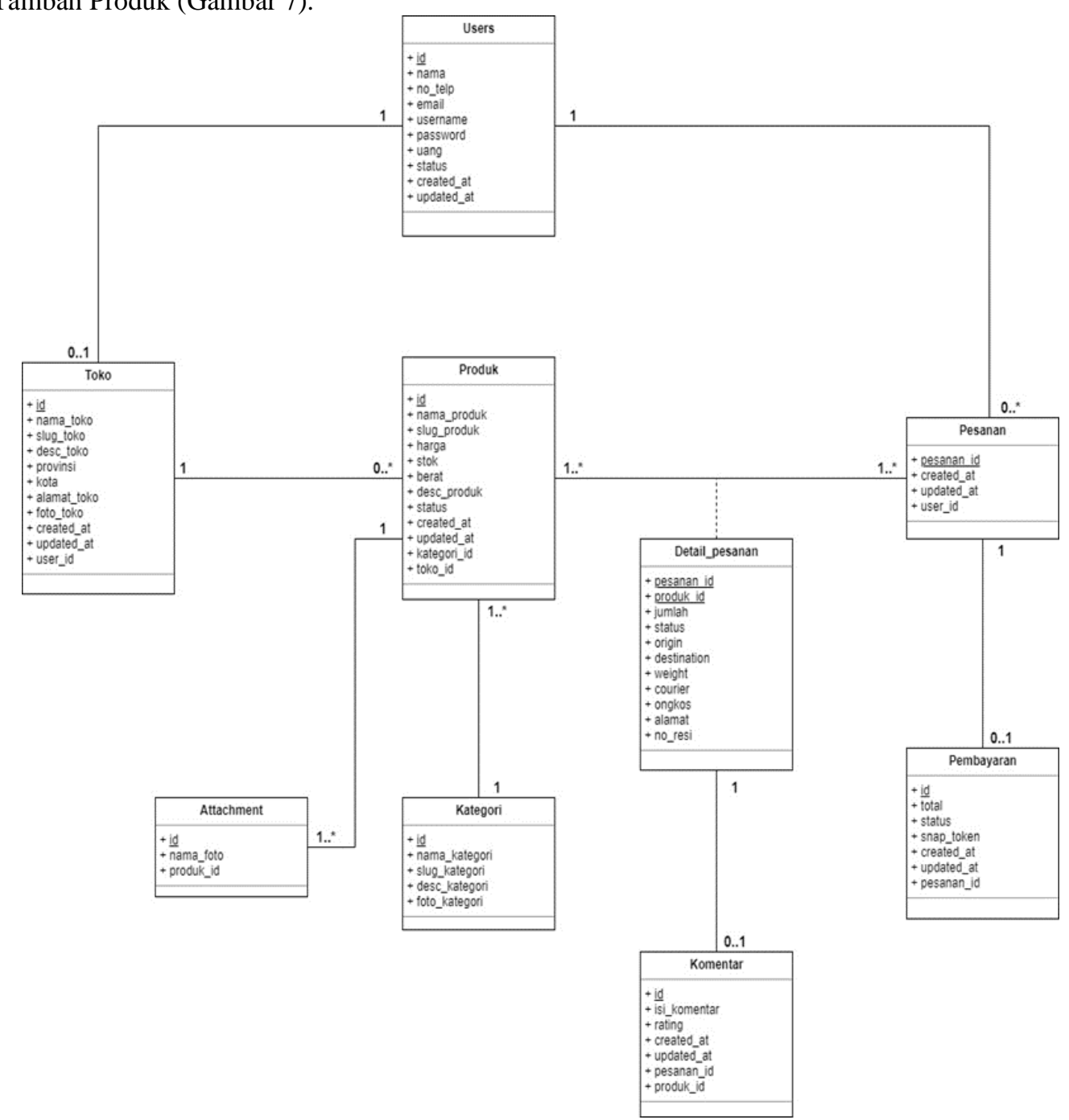

Gambar 5. Class Diagram Marketplace 


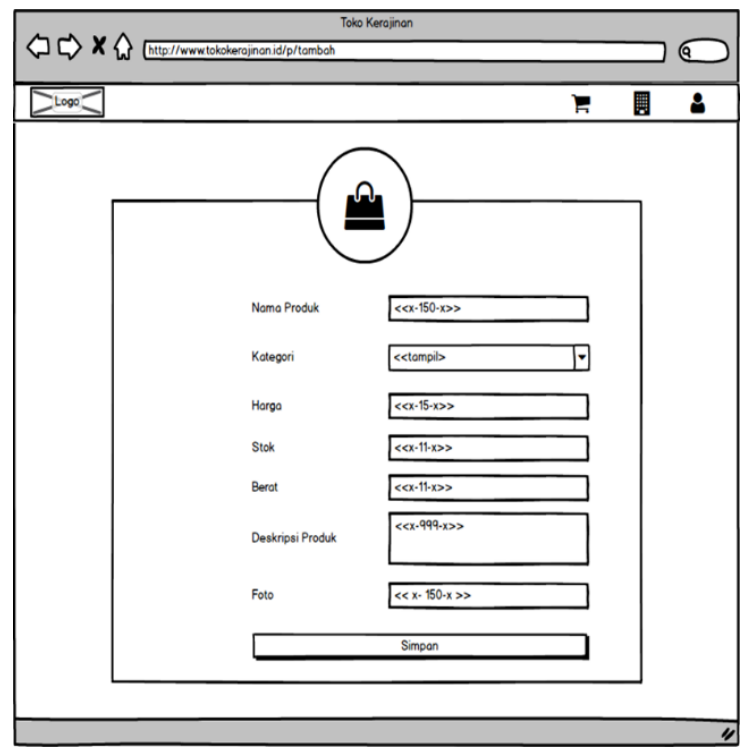

Gambar 6. Rancangan Layar Tambah Produk

Pada Gambar 7 merupakan Sequence Diagram Tambah produk yang digunakan untuk menggambarkan interaksi antara aktor dengan sistem ketika melakukan tambah produk. Interaksi dimulai ketika penjual membuka form tambah produk yang kemudian dilanjutkan dengan menginput data produk. Setelah input selesai maka penjual menekan tombol simpan. Sistem akan menyimpan data produk yang ditambahkan serta menyimpan foto produknya.

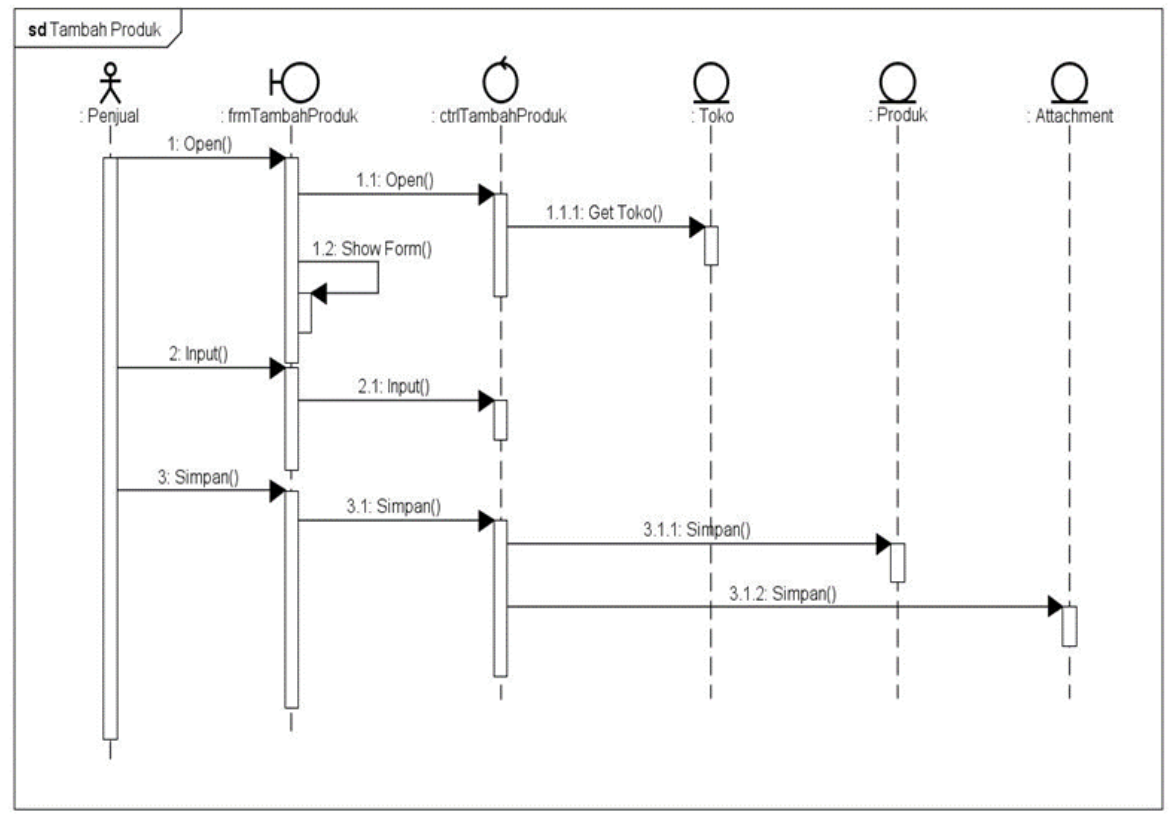

Gambar 7. Sequence Diagram Tambah Produk

Sesuai dengan Use Case Diagram Pembeli (Gambar 3) dibutuhkan keranjang belanja yang digunakan untuk menampung sementara produk-produk yang akan dibeli oleh pelanggan. Oleh karena itu dibuatkan Rancangan Layar Keranjang Belanja (Gambar 8) pada marketplace sehingga pembeli dapat melakukan kegiatan tersebut. Pada interface keranjang belanja ditampilkan data produk yang sudah dimasukan ke dalam keranjang belanja dalam bentuk table, kolom pada keranjang belanjanya yaitu Nomor Urut, Produk (nama produk, gambar produk), Harga Produk, Jumlah produk yang dapat ditambah atau dikurangi, serta subtotal dari perkalian harga produk dengan jumlah. Selain itu pada setiap produk pembeli memilih alamat kirim yaitu provinsi, kota, kurir, layanan yang disediakan kurir, selanjutnya akan tampil biaya kirimmnya. Pada interface keranjang belanja juga terdapat tombol Pembayaran yang digunakan untuk menyelesaikan proses pengisian keranjang belanja. 


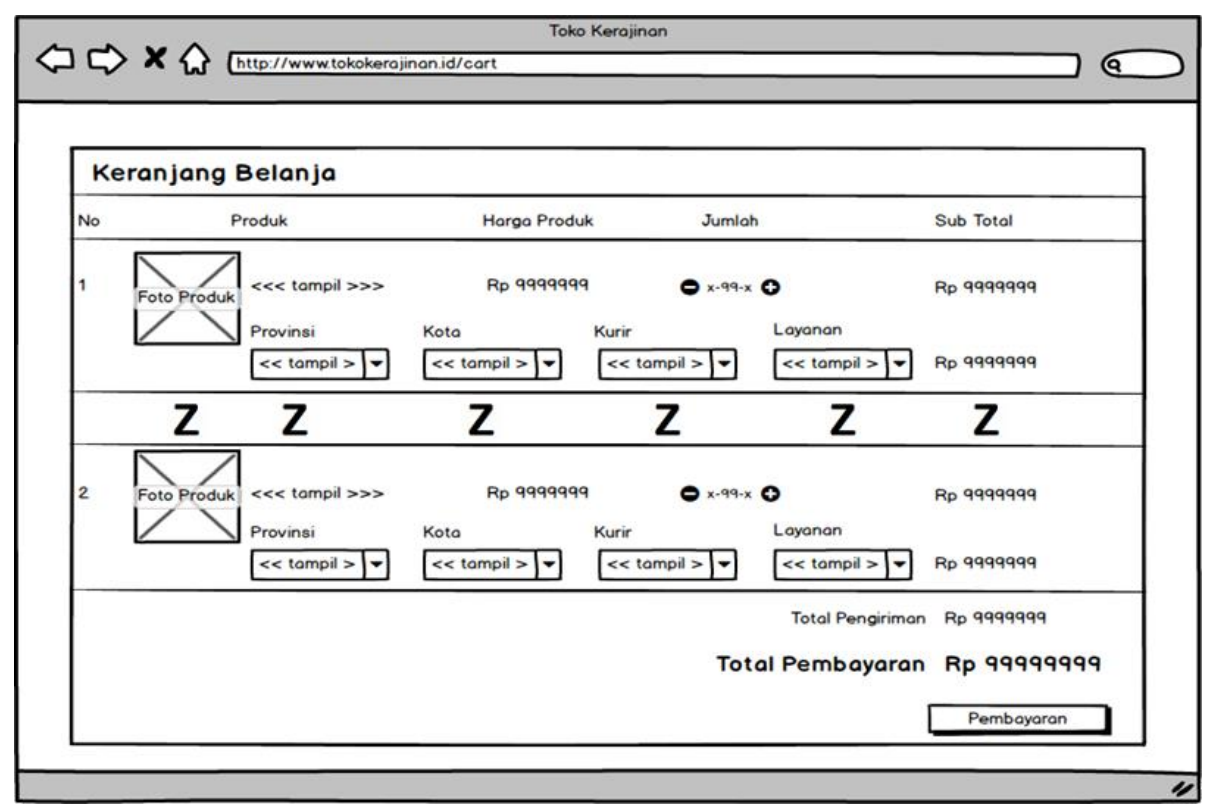

Gambar 8. Rancangan Layar Keranjang Belanja

Gambar 9 merupakan Sequence Diagram Keranjang Belanja yang menggambarkan interaksi antara pembeli dengan website. Interaksi dimulai ketika pembeli membuka halaman data produk, dilanjutkan dengan pembeli menambah produk kedalam keranjang belanja yang mengakibatkan data produk disimpan sementara kedalam keranjang belanja. Selanjutnya pembeli menampilkan halaman keranjang. Terakhir pembeli memilih pengiriman pada keranjang belanja untuk menghitung total pengiriman.

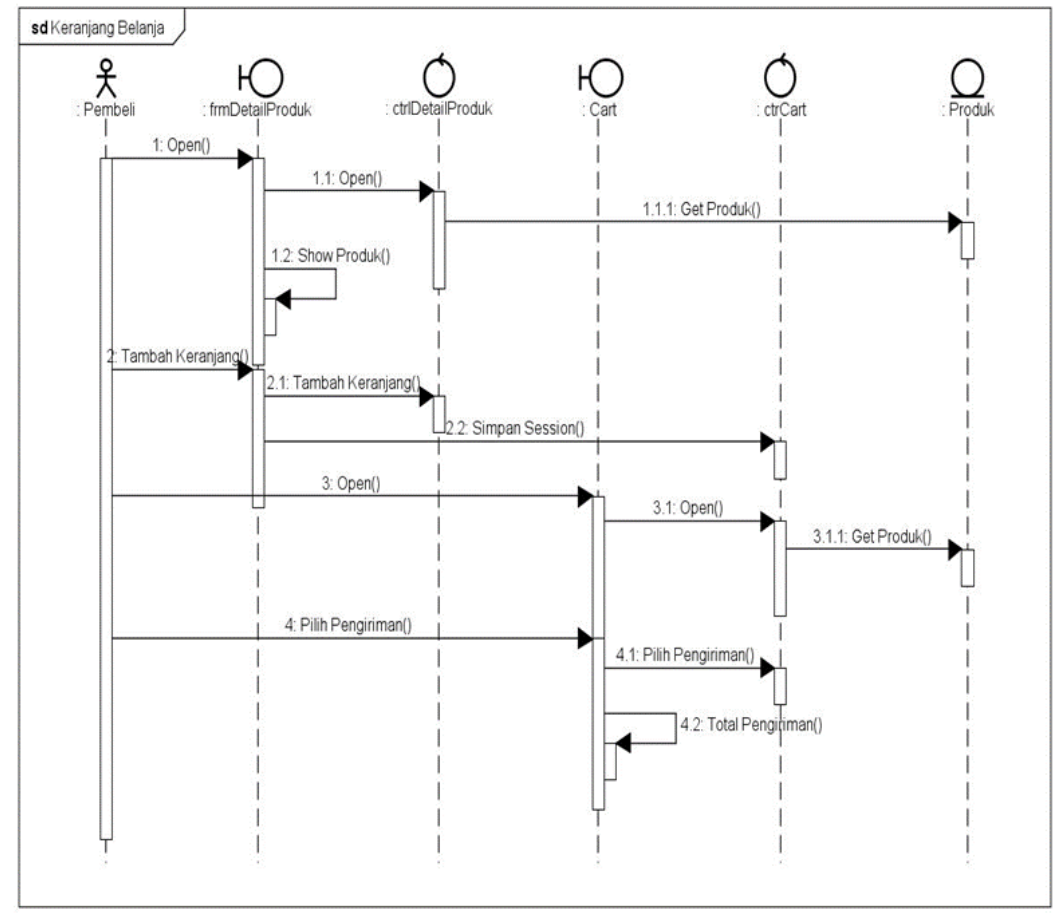

Gambar 9. Sequence Diagram Keranjang Belanja

Pada Gambar 10 merupakan Rancangan Layar Laporan Cashflow yang dibuat sesuai dengan kebutuhan dari Use Case Diagram Admin (Gambar 4). Interface Laporan Cashflow digunakan untuk melihat kondisi keuangan dari marketplace yang menampilkan grafik dari cashflow marketplace. Selain itu juga ditampilkan Total User yang sudah terdaftar, Total Toko yang sudah dibuka pada marketplace, Total Transaksi Berhasil, Total Transaksi Gagal, Total Pengiriman. 


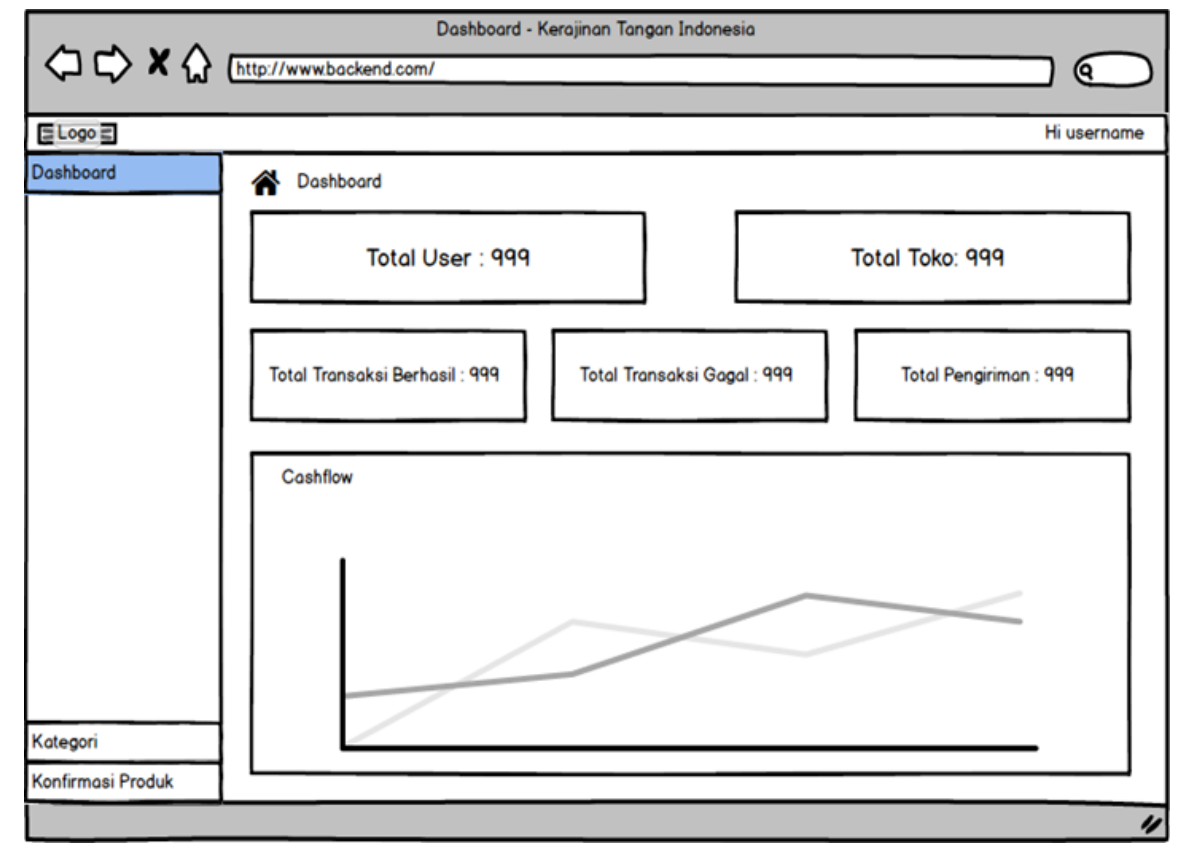

Gambar 10. Rancangan Layar Laporan Cashflow

Interaksi yang terjadi antara admin dengan sistem ketika melihat Laporan Cashflow dapat dilihat pada Gambar 11 yang merupakan Sequence Diagram Laporan Cashflow. Interaksi dimulai ketika pegawai membuka laporan cashflow yang kemudan sistem menampilkan laporan dengan membaca class pesanan, detail_pesanan, dan pembayaran. Kemudian pegawai dapat memilih range tanggal yang diigingkan, perubahan yang dilakukan akan merubah tampilan data pada laporan.

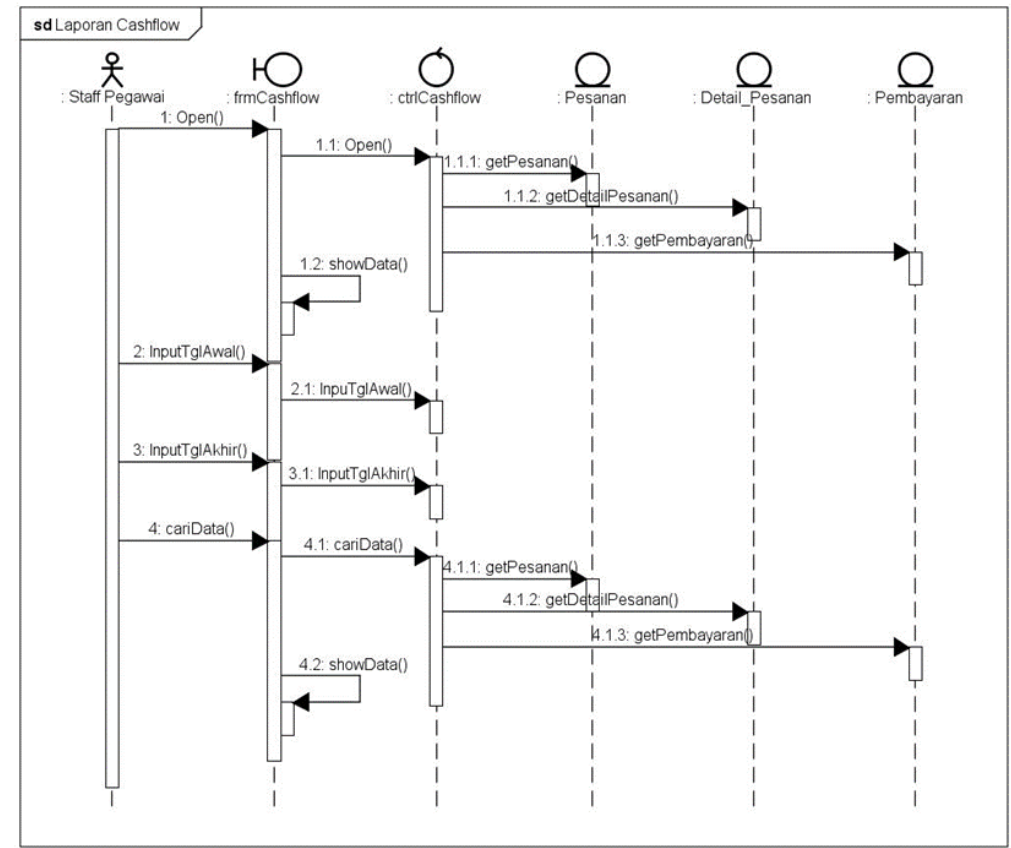

Gambar 11. Sequence Diagram Laporan Cashflow

\subsection{Evaluasi Prototype}

Pengujian Black-box dipilih untuk melakukan evluasi prototype. Pengujian black-box yang dilakukan adalah dengan melakukan proses input pada prototype yang sudah ada kemudian memeriksa hasilnya apakah sesuai dengan yang diharapkan atau tidak. Evaluasi dilakukan pada salah satu interface yaitu Tambah Produk. Tabel pengujian dapat dilihat pada tabel 1 . 
Tabel 1. Pengujian Tambah Kategori

\begin{tabular}{|c|l|l|l|}
\hline No & \multicolumn{1}{|c|}{ Skenario Pengujian } & \multicolumn{1}{c|}{ Hasil Yang Diharapkan } & Hasil Pengujian \\
\hline 1 & $\begin{array}{l}\text { Menyimpan data produk tidak lengkap (ada } \\
\text { kolom yang tidak diisi), apakah bisa } \\
\text { menyimpan data ketika tombol simpan di } \\
\text { klik }\end{array}$ & $\begin{array}{l}\text { Sistem tidak akan menyimpan data ketika } \\
\text { tombol kolom yang diisi (kosong), dan } \\
\text { ketika meng-klik tombol simpan } \\
\text { menampilkan pesan "Terdapat Data } \\
\text { Kosong" }\end{array}$ & $\begin{array}{l}\text { Sesuai dengan hasil } \\
\text { yang diharapkan }\end{array}$ \\
\hline 2 & $\begin{array}{l}\text { Menambah data prdouk, menginput data } \\
\text { dengan lengkap, apakah bias menambah } \\
\text { data ketika tombol simpan di klik? }\end{array}$ & $\begin{array}{l}\text { Sistem sukses menambah data produk } \\
\text { ketika meng-klik tombol simpan dengan } \\
\text { menampilkan "Data Berhasil Disimpan" }\end{array}$ & $\begin{array}{l}\text { Sesuai dengan hasil } \\
\text { yang diharapkan }\end{array}$ \\
\hline
\end{tabular}

Hasil pengujian pada halaman Tambah Produk (Tabel 1) adalah pengujian nomor 1 dan 2 semuanya valid sesuai dengan hasil yang diharapkan.

\section{KESIMPULAN}

Berdasarkan masalah yang terjadi dan perancangan sistem marketplace yang dibuat untuk memecahkan masalah maka dapat disimpulkan sebagai berikut:

a. Pengerajin lokal memerlukan sebuah tempat khusus untuk menjual hasil karya mereka namun tempat tersebut haruslah mudah diakses oleh calon pembeli sehingga calon pembeli tidak merasa kesulitan. Dengan adanya marketplace kerajinan tangan ini, penjual dapat memasarkan hasil karya mereka yang langsung dapat dilihat produknya oleh calon pembeli dan mempermudah proses transaksi pembelian.

b. Marketplace Kerajinan Tangan membuat laporan-laporan yang digunakan untuk membuat suatu keputusan. Marketplace yang dirancang masih terdapat beberapa kekurangan antara lain:

a. Marketplace dibuat berdasarkan obyek penelitian yaitu kerajinan tangan

b. Belum adanya return produk yang dibeli tidak sesuai dengan pemesanan

c. Belum adanya menu filter pada pencarian produk

d. Perlu diimplementasikan Search Engine Optimization (SEO) baik On Page maupun Off Page untuk menarik pengunjung ke website

\section{DAFTAR PUSTAKA}

[1] R. Marco and B. Puspa Ningrum, “Analisis Sistem Informasi E-Marketplace Pada Usaha Kecil Menengah (UKM) Kerajinan Bambu Dusun Brajan,” Data Manajemen dan Teknologi Informasi, vol. 18, no. 2, pp. 48-53, 2017.

[2] A. K. Putra, R. D. Nyoto, and H. S. Pratiwi, "Rancang Bangun Aplikasi Marketplace Penyedia Jasa Les Private Di Kota Pontianak Berbasis Web," Jurnal Sistem dan Teknologi Informasi, vol. 5, no. 1, pp. 22-25, 2017.

[3] A. Nur Ngazis, "Qlapa, Startup Indonesia Paling Menjanjikan Kini Bangkrut," viva.co.id, 2019. [Online]. Available: https://www.viva.co.id/digital/startup/1127558-qlapa-startup-indonesia-paling-menjanjikan-kini-bangkrut. [Accessed: 17-Oct-2019].

[4] A. Osterwalder and Y. Pigneur, Business Model Generation A Handbook for Visionaries, Game Changers, and Challengers. Germany: Wiley, 2013.

[5] H. Warnaningtyas, "Desain Bisnis Model Canvas ( BMC ) Pada Usaha Batik Kota Madiun," EKOMAKS J. Manajemen, Ilmu Ekon. Kreat. dan Bisnis, vol. 9, no. 79, pp. 52-65, 2020.

[6] A. Mubarak, "Rancang Bangun Aplikasi Web Sekolah Menggunakan Uml (Unified Modeling Language) Dan Bahasa Pemrograman Php (Php Hypertext Preprocessor) Berorientasi Objek," JIKO (Jurnal Inform. dan Komputer), vol. 2, no. 1, pp. 19-25, 2019.

[7] W. Nugraha and M. Syarif, "Penerapan Metode Prototype Dalam Perancangan Sistem Informasi Penghitungan Volume Dan Cost Penjualan Minuman Berbasis Website," JUSIM (Jurnal Sist. Inf. Musirawas), vol. 3, no. 2, pp. 94-101, 2018.

[8] T. A. Kurniawan, "Pemodelan Use Case (UML): Evaluasi Terhadap beberapa Kesalahan dalam Praktik," J. Teknol. Inf. dan Ilmu Komput., vol. 5 , no. 1 , p. 77,2018

[9] Saifulloh, R. Pamungkas, T. D. Saputro, and F. R. Al-ayyubi, "Perancangan Prototype Pengelolaan Arsip Surat di Dinas Lingkungan Hidup Kota Madiun," J. Altifani, vol. 1, no. 1, pp. 35-42, 2021.

[10] M. R. Asyari and S. Ramadhani, "Sistem Informasi Arsip Surat Menyurat," J. Teknol. dan Inf. Bisnis, vol. 3, no. 1, pp. 175-184, 2021. 